Febr. 1880, p. 122) aufzuführen vergessen, wohl aber die Gattung Isandula Thomson (Naturaliste II, October 1880, p. 294) citirt, welche mit derselben identisch ist.

Von Thomson's wenigen Merkmalen ist richtig: corpus angustatum; der clypeus antice medio tuberculatus feblt bei Het. mutica Harold.

Dr. G. Kraatz.

\title{
Phyllopertha humeralis n. sp. aus Kleinasien.
}

Oblonga, fere glabra, nigra, antennarum basi, capite ante oculos, thorace toto, elytrorum macula oblonga humerali apiceque pedibusque femorum basi excepta rufo-testaceis. - Long. 7-8 mill.

Merklich gröfser als Phyllop. frontalis Weise (Ins. Deutschlands VI), der schwarze Fleck auf den Fld. gröfser, bis an die Naht und fast an den Aufsenrand reichend, die Beine lebbaft röthlich gelb, die vorderen an der Basis, die hinteren bis über die Mitte schwärzlich. Die Fühler sehr schlank, die 4 ersten Glieder röthlich gelb, das 4. an der Spitze gebräunt. Der Kopf ganz ähnlich gezeichnet wie bei frontalis, d. h. hinter den gelblichen Fühlerbuckeln und dem Quereindruck schwarz, glänzend. Das Halsschild quer, rothgelb, mit deutlich stumpfwinkligen Hinterecken, der Hinterrand nach dem Seitenrande zu etwas vorgezogen. Schildchen schwarz. Die Fld. sind von der gewöhnlichen Form, fein punktulirt, ein schlanker (fast doppelt so lang als breiter), mit geradem Innenrande und die Spitze desselben gelb, die Naht ganz schwarz, nur der äufserste Aufsenrand gelb. Die Unterseite schwarz. Die Vorderbeine vorn ganz gelb. Die Schenkel hinten bis fast zur Mitte schwarz; die Mittelschenkel bis zur Mitte schwarz, die Hinterschenkel bis über die Mitte schwärzlich, die Hüften braun oder gelblich.

Ein muthmafslich weibliches Ex. in der Sammlung des Herrn v. Heyden von Herrn Krieghoff aus Kleinasien eingesendet.

Die gröfste Art der Gattung, an der Färbung der Beine leicht kenntlich.

Dr. G. Kraatz. 


\section{$2 \mathrm{BHL}$ Biodiversity Heritage Library}

Kraatz, G. 1891. "Phyllopertha humeralis n. sp. aus Kleinasien." Deutsche entomologische Zeitschrift 1891(1), 124-124.

https://doi.org/10.1002/mmnd.48018910119.

View This Item Online: https://www.biodiversitylibrary.org/item/103415

DOI: https://doi.org/10.1002/mmnd.48018910119

Permalink: https://www.biodiversitylibrary.org/partpdf/235483

\section{Holding Institution}

Harvard University, Museum of Comparative Zoology, Ernst Mayr Library

\section{Sponsored by}

Harvard University, Museum of Comparative Zoology, Ernst Mayr Library

\section{Copyright \& Reuse}

Copyright Status: Public domain. The BHL considers that this work is no longer under copyright protection.

This document was created from content at the Biodiversity Heritage Library, the world's largest open access digital library for biodiversity literature and archives. Visit BHL at https://www.biodiversitylibrary.org. 